\title{
Cuando amar era pecado. Sexualidad, poder e identidad entre los sodomitas coloniales (Virreinato del Perú. Siglos XVI-XVII)
}

* Fernandamolina

Travaux de l'Institut Français d’Études Andines.

Lima; La Paz: Instituto Francés de Estudios Andinos (IFEA); Plural Editores 2017 | ISBN: 0768-424X | 179 pp.

DOI: https://doi.org/10.22380/20274688.520

ANDREA BARRERO CAMACHO

Universidad Andina Simón Bolívar, sede Ecuador

A partir de la década de 1980, los estudios de género pusieron en la palestra A otras dimensiones de las relaciones sociales entre los individuos. Así, la feminidad y la masculinidad, en cuanto fenómenos históricamente constituidos, fueron cuestionados, debatidos y reconceptualizados. Sin embargo, en el campo de los estudios coloniales son pocos los que han indagado acerca de las prácticas, las transgresiones y los delitos sexuales. Cuando amar era pecado. Sexualidad, poder e identidad entre los sodomitas coloniales (Virreinato del Perú. Siglos XVI-XVII), tesis doctoral de la historiadora argentina Fernanda Molina, ahonda justamente en dichos campos, haciendo énfasis en la sodomía masculina en la sociedad colonial peruana entre los siglos XVI y XVII, a partir de un minucioso análisis metodológico, conceptual y heurístico.

La investigación, dividida en cinco capítulos además de las conclusiones, centra su atención en la sodomía desde puntos de vista heterogéneos pero complementarios, entre los que se destacan la justicia, la religión, la cultura, el 
poder y la identidad. De esta manera, la autora es capaz de aprehender y analizar un fenómeno considerado por muchos como transhistórico. El primer capítulo, titulado "Sodomía", acerca al lector a las definiciones sobre sexualidad que se tenían y debatían durante la época estudiada. En otras palabras, Molina da una explicación de cómo juristas, teólogos y moralistas entendieron las diferentes prácticas sexuales. La base de este debate estuvo en la escolástica tomista, la cual se enfocó en caracterizar los "pecados de lujuria”, es decir, cualquier práctica sexual que no tuviera como finalidad la reproducción. Dentro de la escala propuesta, los pecados contra natura — bestialismo, molicies (masturbación) y sodomía - se consideraban como los más transgresores de la ley natural. La autora hace énfasis en que estas prácticas sexuales fueron consideradas delitos, como resultado del pluralismo jurídico vigente en la época. Finalmente, Molina hace una reflexión conceptual crítica sobre el término sodomía, pues más allá del uso peyorativo que haya podido tener en la época de estudio, es una representación discursiva capaz de dar sentido a una experiencia (sexual) que trascendió las interpretaciones de teólogos y juristas.

Por su parte, el capítulo 2, titulado "Justicia", hace hincapié en la superposición jurisdiccional de la sodomía e intenta explicar cómo su carácter mixti for - pecado y delito a la vez- fue resultado de la integración de diversas fuentes de derecho, en especial el romano y el canónigo, que terminaron constituyéndose en ius comune, derecho común. Según la autora, la vigencia del ius comune en el virreinato peruano respondió a la necesidad de sentar jurisprudencia dentro de su nueva jurisdicción. Por lo tanto, el pluralismo jurídico fue resultado de la competencia y la cooperación de las distintas fuentes de derecho vigentes en la Península en el momento de la Conquista, que incluían corpus jurídicos como las Siete Partidas, las Leyes del Toro, el derecho canónico, el derecho común y, posteriormente, las Leyes de Indias. Esta conjunción, como bien señala la autora, da cuenta del estrecho vínculo entre la Península y los territorios de ultramar.

La importancia de tener claro el carácter mixti fori de la sodomía y de la dualidad jurídica radica en la conflictividad jurisdiccional de la que era sujeto la sodomía y que, de cierta forma, limitaba la actuación de la justicia civil y eclesiástica. Como sostiene Molina, acertadamente, la cultura jurídica del Antiguo Régimen, a partir del corporativismo, permitió la existencia de fueros especiales que sirvieron de refugio para quienes gozaban de aquellos privilegios. En consecuencia, los fueros se convirtieron en una estrategia efectiva para eludir el castigo judicial. Así, su uso muestra (¿claramente?) la doble vara con la que 
era administrada la justicia colonial, pues refleja los privilegios o las limitaciones que los acusados tenían a partir de su calidad y los preconceptos que sobre ellos había, considerando su posición social o étnica.

En el tercer capítulo, "Poder", Molina analiza la correspondencia entre dominación social y dominación sexual, con base en la idea de que la relación sexual en cuanto relación de poder constituye un acto de dominación masculina sobre el cuerpo femenino, por lo que las relaciones sexuales entre hombres deben ser entendidas e interpretadas bajo los mismos parámetros. En este sentido, la autora analiza las maneras en que las prácticas sodomíticas entre hombres de distintas calidades podían reproducir o subvertir las relaciones de dominación, así como las jerarquías sociales y étnicas. Para cumplir su propósito, centra su atención en algunos espacios en los cuales las relaciones sociales, culturales y étnicas eran desiguales, como los espacios domésticos, los monasterios e iglesias, y los naos; en todos ellos, las jerarquías sociales y las relaciones de dominación, poder y dependencia son claras.

De la mano con lo anterior, con acierto, la autora se pregunta en qué medida los vínculos sexuales sodomíticos fueron consensuados y no resultado de la relación de dependencia existente entre los sujetos involucrados. En otras palabras, hasta qué punto las jerarquías impuestas por el sistema estamental colonial fueron suficientes o no para doblegar la voluntad de los sujetos dominados. Este análisis la lleva a concluir que en muchos casos la coerción se impuso en aquellas relaciones donde existía un vínculo de dependencia. Empero, en otros, ello no fue suficiente para doblegar la voluntad del sujeto dominado.

Aún más, considerando la complejidad de la realidad colonial, Molina señala que no todas las relaciones sodomíticas fueron un reflejo de las relaciones de poder, pues algunas fueron consensuadas. En muchas de estas el vínculo afectivo entre los sujetos, o por lo menos por parte de uno, era evidente. Las relaciones se caracterizaron, además, por subvertir, alterar y cuestionar las posiciones y las relaciones sociales, étnicas y de poder, pues en muchos casos los involucrados tenían un estatus diferente. La posibilidad de alterar y moldear las posiciones sociales, tal como señala Molina al final del capítulo, fue el fruto de la propia naturaleza de la sociedad colonial, fundada en la movilidad y la permeabilidad social desde el momento mismo de la Conquista.

Por su parte, el cuarto capítulo, titulado "Religión”, retoma algunos conceptos ya abordados en el primero, haciendo hincapié en las instituciones religiosas coloniales y el desafío que enfrentaron al crear una doctrina cristiana sobre la sexualidad. De este modo, es posible analizar e interpretar la lucha 
contra la sodomía durante el periodo estudiado, a partir del accionar de la Inquisición y de las autoridades eclesiásticas, a la vez que aprehender el afán de estas por disciplinar a los "cristianos viejos", implantando un nuevo modelo de moralidad en un universo de relajación sexual. Es menester señalar que Molina menciona que el interés que mostraron las autoridades eclesiásticas por el disciplinamiento sexual de los “cristianos viejos” tenía un propósito pedagógico, el cual consistía en no expandir las costumbres nefandas en los territorios de ultramar. Por ello, la Inquisición tuvo jurisdicción sobre los llamados "cristianos viejos" y no así sobre los neófitos indígenas.

De la mano con lo anterior, se menciona que todos estos esfuerzos fueron fruto de las reformas tridentinas, las cuales tuvieron eco dentro del Tercer Concilio Limense. Sin embargo, a pesar de los intentos por controlar las almas y los cuerpos, la administración de justicia eclesiástica, cuando se trataba de cuestionar la sodomía, mostró cierta laxitud, tolerancia e incluso complicidad con algunos acusados, en especial con los miembros del clero y sus escandalosas costumbres sexuales.

Finalmente, el quinto capítulo, que lleva por título "Identidad", es una aproximación a la subjetividad de los sodomitas virreinales a partir de sus experiencias sexuales. El propósito de Molina es evaluar la posibilidad de que las prácticas sodomíticas coadyuvaran a la construcción de una identidad de género y sexual. La autora parte de la relación entre sexualidad y género, categorías analizadas desde una perspectiva histórica, para explicar la formación de sexualidades "premodernas". De esta forma, se argumenta que dichas sexualidades estuvieron atravesadas por el placer, la afectividad, la intimidad, la sensibilidad física y psicológica, además del peso jurídico-teológico que sobre ellas recaía, razón por la cual los sodomitas virreinales constituyeron sujetos sociales complejos que deben ser entendidos en el marco de sus experiencias.

Las propuestas teóricas, las reflexiones y las conclusiones a las que llega Molina, además de estar acompañadas de un debate y diálogo reflexivo con diversos autores, son sin duda una de las fortalezas de la obra. La reflexión teórica va acompañada de una base documental abordada de manera crítica. Los estudios de caso, además de dar cuenta de ciertas generalidades, refuerzan la idea de que cada experiencia fue única, reflejando así la complejidad del fenómeno de la sodomía en la sociedad colonial peruana. Paralelamente, el uso mesurado de conceptos y categorías permite abordar y entender la sodomía en el contexto histórico y conceptual en el que se desarrolló, evitando de esta manera caer en anacronismos y conclusiones forzadas. 
Sin embargo, al estar basado en fuentes documentales oficiales, el trabajo ofrece una versión un tanto parcializada del pecado de sodomía, pues no solo da cuenta de los casos que llegaron a los tribunales, sino que ellos están mediados por las autoridades judiciales y las declaraciones de los testigos. Esta característica de la documentación utilizada limita la exploración de la subjetividad de los sodomitas, pues esta se construye más con base en la percepción que los demás tenían de ellos que desde su propio punto de vista.

Más allá de esta pequeña observación, creemos que los aportes de la investigación son evidentes. El trabajo de Molina es pionero en el territorio andino, pues toca un tema muy poco analizado por los estudios de género: la sexualidad masculina. Como se puede evidenciar a lo largo del trabajo, la transgresión sexual masculina trastocó los roles de género asignados y las jerarquías sociales coloniales. La construcción de la sexualidad como fenómeno histórico no puede ser entendida dejando de lado aquellas consideradas como transgresoras o contra natura, pues ellas reflejan la manera en que la sexualidad fue objeto de control y disciplinamiento a lo largo de varios siglos. Finalmente, el trabajo nos acerca a la vida cotidiana de sujetos invisibilizados, juzgados y castigados por ser ellos mismos, invitándonos de esta manera a pensar y reflexionar sobre un tema que aún hoy continúa siendo un tabú. 